\title{
Effect of Free-standing Al/Ni Exothermic Film on Thermal Resistance of Reactively Bonded Solder Joint
}

\author{
Shunsuke Kanetsuki, ${ }^{1,2^{*}}$ Shugo Miyake, ${ }^{3}$ and Takahiro Namazu ${ }^{2}$ \\ ${ }^{1}$ Kobelco Research Institute, Inc., 2222-1 Ikeda, Onoe, Kakogawa, Hyogo 675-0023, Japan \\ ${ }^{2}$ Department of Mechanical Engineering, Aichi Institute of Technology, \\ 1247 Yachigusa, Yakusa, Toyota, Aichi 470-0392, Japan \\ ${ }^{3}$ Kobe City College of Technology, 8-3 Gakuen-Higashimachi, Nishi-ku, Kobe, Hyogo 651-2194, Japan
}

(Received August 6, 2018; accepted November 14, 2018)

Keywords: Al/Ni multilayer, self-propagating exothermic reaction, solder bonding, free-standing film, thermal resistance, void, crack

In this study, a free-standing $\mathrm{Al} / \mathrm{Ni}$ exothermic multilayer is fabricated and used as a heat source for reactive soldering, instead of an $\mathrm{Al} / \mathrm{Ni}$ film directly deposited on the solder layer. The free-standing film enables us to reduce not only cracking in the reacted NiAl layer but also voiding at the NiAl-solder interface. These positive effects have successfully resulted in the reduction in the thermal resistance of the joint. Electron probe microanalysis (EPMA) and electron backscattering diffraction (EBSD) analyses suggest that reducing the thermal resistance has been caused by mechanical strain originating from volume shrinkage induced by the $\mathrm{Al} / \mathrm{Ni}$ exothermic reaction as well as heat conduction from the reactive film to the solder layer. The mechanism of reducing the number of voids is discussed in light of stress distribution during reactive bonding.

\section{Introduction}

Multilayer metallic films made of light and transition metals, such as $\mathrm{Al}$ and $\mathrm{Ni}$, show selfpropagating explosive reaction during intermetallic compound formation. ${ }^{(1-4)}$ The exothermic performance of the films is tunable by controlling their deposition conditions. In the case of an $\mathrm{Al} / \mathrm{Ni}$ multilayer film with an atomic content ratio of 1:1 and a bilayer thickness of $100 \mathrm{~nm}$, the heat energy can be estimated to be around $1300 \mathrm{~J} / \mathrm{g} .{ }^{(5)}$ The self-propagation speed of the reaction is also tunable within the range from 1 to $20 \mathrm{~m} / \mathrm{s} .{ }^{(6,7)}$ These attractive characteristics enable us to use the reactive film as a local heat source for soldering. ${ }^{(8-10)}$ In the soldering application, there are numerous merits, such as easy film preparation, almost zero power for ignition, instant and local heating, unnecessary circuits for the reaction (self-propagation of the reaction), unnecessary furnaces, zero emission, and low cost. In the near future, if we replace conventional soldering technologies using furnaces with this reactive soldering technology in manufacturing semiconductors and MEMS microdevices, the amounts of energy used and $\mathrm{CO}_{2}$

*Corresponding author: e-mail: kanetsuki.shunsuke@kki.kobelco.com

https://doi.org/10.18494/SAM.2019.2076 
emission will be markedly reduced in the world because these industries are, needless to say, expected to blossom more and more over the coming decades.

In recent studies, toward the practical use of the reactive bonding technique, researchers in related work understand well that there are several technical problems such as cracking, ${ }^{(11)}$ void generation, ${ }^{(12)}$ mechanical weakness, ${ }^{(13,14)}$ and high thermal resistance. ${ }^{(15)}$ The authors are working on controlling the NiAl-solder interface and are attempting to reduce the number of voids and cracks at solder joints. The bonded section obtained by the Al/Ni exothermic reaction is called a "reactively bonded solder joint".

Figure 1 summarizes our previous work and shows thermal resistance measurement results of reactively bonded solder joints using an $\mathrm{Al} / \mathrm{Ni}$ explosive reactive film. In this process, two different types of bonded interface between the reacted NiAl and solder are obtained. The interface between NiAl and the bottom-side solder is called the "prebonded interface", and that at the top-side one is called the "newly bonded interface" [Fig. 1(a)]. In reactive bonding, a higher normal load contributed to a reduction in the number of voids at the reacted NiAl-solder interface on the bottom side, leading to a decrease in the thermal resistance between two $\mathrm{Si}$ chips [Fig. 1(b)]. This is a result of the higher efficiency of heat conduction from the heat layer to the solder during instantaneous heating. ${ }^{(16)}$ Controlling the $\mathrm{Al} / \mathrm{Ni}$ film-solder interface was

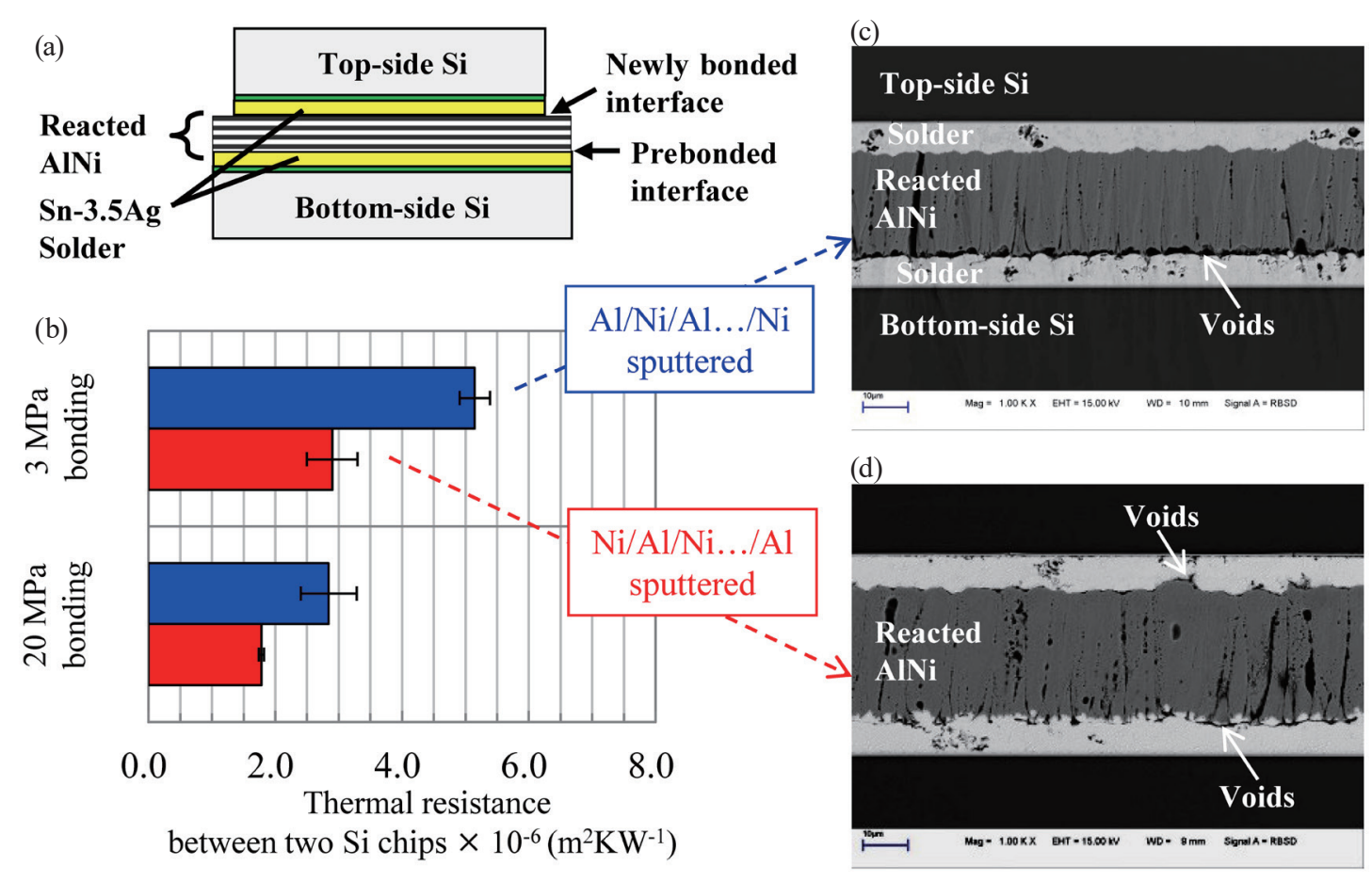

Fig. 1. (Color online) Summary of our previous work. (a) Schematic showing the reactive soldering of two chips. (b) Thermal resistance between two Si chips bonded at 3 and $20 \mathrm{MPa}$. The blue bars show that Al/Ni/Al.../Ni multilayers are sputtered on the bottom-side $\mathrm{Si}$, and the red ones show Ni/Al/Ni.../Al multilayers. Cross-sectional SEM images of the bonded solder joints: (c) $\mathrm{Al} / \mathrm{Ni} / \mathrm{Al}$.../Ni (d) Ni/Al/Ni.../Al sputtering cases. 
also effective for reducing thermal resistance, as it is well known that the Sn-3.5Ag solder has good chemistry with Ni compared with $\mathrm{Al}^{(17)}$ By applying a Ni layer onto the solder on both sides, the number of voids at the interface could be reduced. ${ }^{(18)}$ This would be related to the formation of a SnNi intermetallic compound at the interface.

In those previous studies, we noted that the number of voids was higher at the prebonded interface (on the bottom side) than at the newly bonded interface (on the top side), as shown in Figs. 1(c) and 1(d). If the bottom-side interface can be prepared as a newly bonded interface, the number of voids could be reduced. That is, using not an $\mathrm{Al} / \mathrm{Ni}$ film directly deposited on the solder layer but a "free-standing" Al/Ni multilayer could be effective in restraining void generation. To realize this, in this study, we use a free-standing $\mathrm{Al} / \mathrm{Ni}$ exothermic reactive film to reactively bond two solder-deposited Si chips with a solder film. The effect of the freestanding reactive film on the numbers of voids and cracks in the solder joint after reactive bonding will be discussed in light of cross-sectional SEM, electron probe microanalysis (EPMA), and electron backscattering diffraction (EBSD) analysis results.

\section{Experimental Procedure}

First, we refer to the reactive soldering using $\mathrm{Al} / \mathrm{Ni}$ film in our previous work [Fig. 1(a)]. A 30-mm-thick Al/Ni multilayer film with a bilayer thickness of $100 \mathrm{~nm}$ (atomic ratio of $\mathrm{Al}: \mathrm{Ni}=1: 1$; $\mathrm{Al}$ and Ni layer thicknesses of 60 and $40 \mathrm{~nm}$, respectively) was deposited on a 12-mm-thick Sn-3.5Ag solder film on the bottom-side Si chip only. After a Si chip (top-side $\mathrm{Si}$ ) without an $\mathrm{Al} / \mathrm{Ni}$ multilayer film was placed on the $\mathrm{Si}$ chip (bottom-side $\mathrm{Si}$ ) with the film, an Al/Ni film was ignited by a spark under a normal load of 3 or $20 \mathrm{MPa}$ in vacuum to induce instantaneous reactive bonding. In the $\mathrm{Al} / \mathrm{Ni}$ film deposition, when a 60 -nm-thick $\mathrm{Al}$ layer is deposited first on a solder film, a 40-nm-thick Ni layer is on the top surface of the bottom-side Si chip, because the $\mathrm{Al}$ and $\mathrm{Ni}$ layers were deposited in turn to control the atomic ratio of 1:1 for $\mathrm{Al}$ and $\mathrm{Ni}$. In the case of using the "as-sputtered" Al/Ni multilayer film, the cross-sectional SEM images of the bonded chip show that there are many voids at the NiAl and bottom-side solder interface, whereas there are no voids at the NiAl and top-side solder interface [Fig. 1(c)]. When the deposition order was inversed, that is, a Ni layer was deposited first, the number of voids at the NiAl and bottom-side solder interface was definitely reduced [Fig. 1(d)]. This would be related with the formation of a SnNi intermetallic compound. ${ }^{(18)}$ Note that, however, almost no voids were found at the other interface regardless of the combination of Al and Sn (although some sub-microsized voids were newly produced); that is, the number of voids was less in the newly bonded interface regardless of the combination of atoms. Consequently, we experimentally confirmed that the solder joints with the voidless interface had a low-thermal-resistance bonded section.

Considering the above results, we examined the effect of using a "free-standing" $\mathrm{Al} / \mathrm{Ni}$ multilayer film for producing a solder joint having low thermal resistance, as shown in Fig. 2. The outermost layers were set to be 40 -nm-thick Ni in consideration of affinity to Sn, although the atomic ratio of the entire film slightly deviates from 1:1 for Al:Ni. A finely polished $\mathrm{Cu}$ sheet was used as a substrate for depositing the $\mathrm{Al} / \mathrm{Ni}$ multilayer film with the entire film 


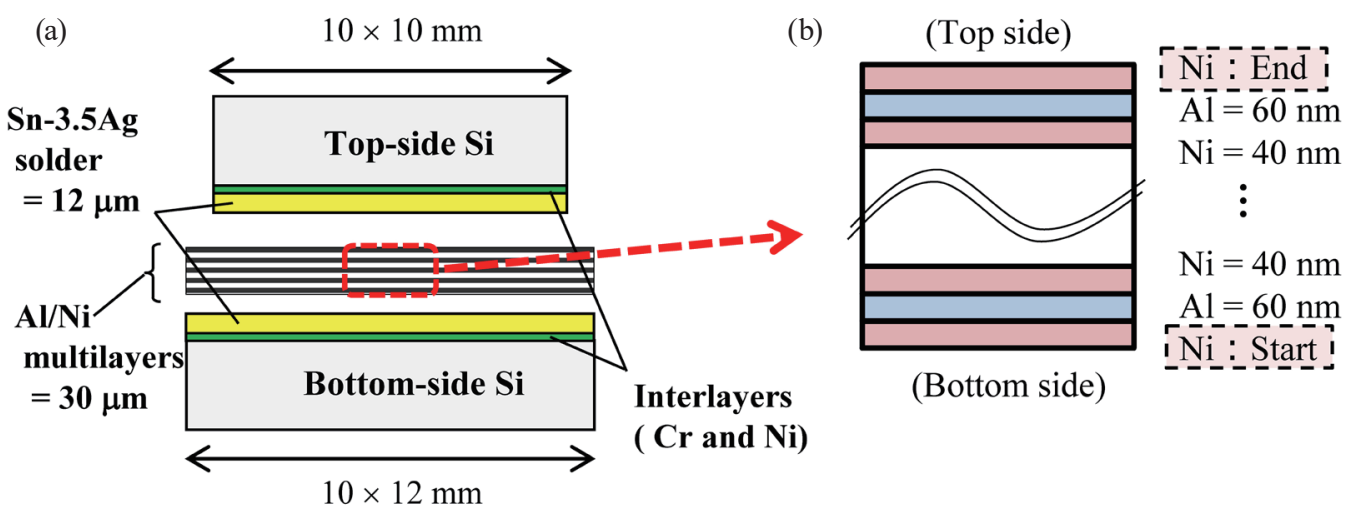

(c)

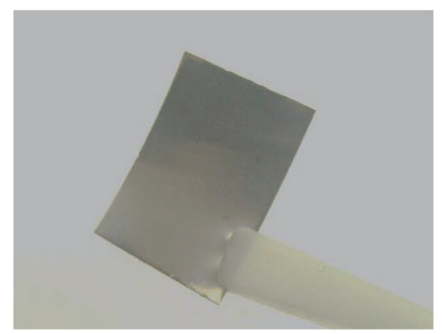

(d)

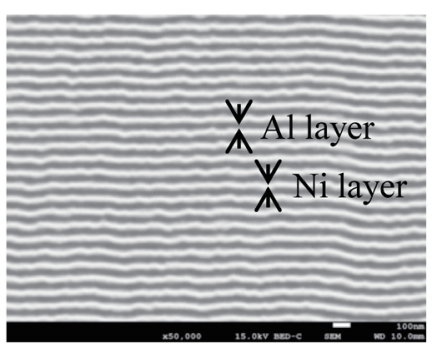

(e)

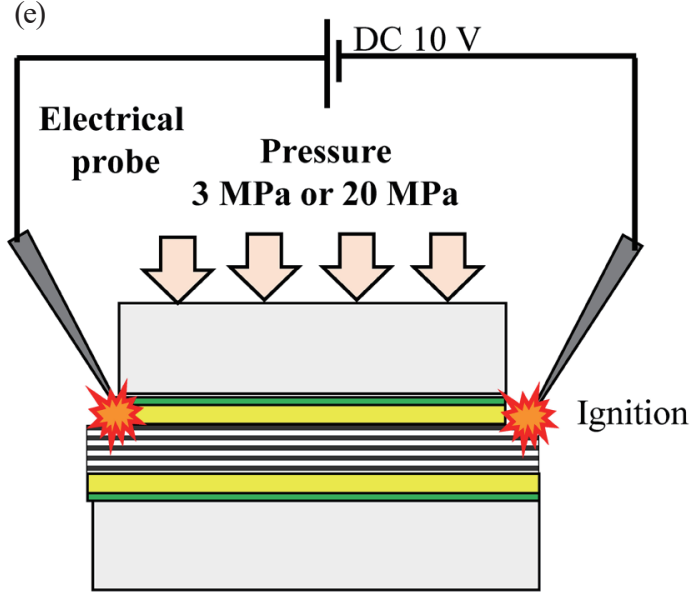

Fig. 2. (Color online) Fabrication of reactively bonded solder joint. (a) Schematic showing the reactive soldering of two chips using reactive $\mathrm{Al} / \mathrm{Ni}$ multilayers before bonding. (b) $\mathrm{Al} / \mathrm{Ni}$ multilayer composition. (c) Exterior photo and (d) cross-sectional image of free-standing Al/Ni multilayer. (e) Schematic of reactive soldering.

thickness of $30 \mathrm{~mm}$. An in-house ternary-source dc magnetron sputtering apparatus was used for the deposition. Then, a $\mathrm{Cu}$ etchant (CuE-3000M made by Wako Pure Chemical Industries, Ltd.) was used to remove $\mathrm{Cu}$ only for releasing the $\mathrm{Al} / \mathrm{Ni}$ multilayer film. After etching, we examined for any visible chemical damage in all the free-standing $\mathrm{Al} / \mathrm{Ni}$ multilayer films used here. A 12-mm-thick Sn-3.5Ag solder film was deposited on diced Si chips with $\mathrm{Cr}$ and $\mathrm{Ni}$ thin interlayers to improve adhesion. After the two Si chips sandwiched a self-standing $\mathrm{Al} / \mathrm{Ni}$ multilayer film, an electric spark was applied to the reactive film under a constant normal load of 3 or $20 \mathrm{MPa}$ in vacuum.

The thermal resistance was measured by the laser flash method with response function analysis. ${ }^{(19)}$ All the experiments were performed at room temperature in air using the ULVAC TC7000 system by the same procedure as described in our previous work, ${ }^{(15,16,18)}$ and three 
fabricated specimens each were used for the as-sputtered and free-standing $\mathrm{Al} / \mathrm{Ni}$ joint. When a pulsed laser is incident on the planar surface of a specimen, one-dimensional thermal diffusion occurs. Then, at the back surface, a time-dependent temperature change is observed using a radiation thermometer. The thermal resistance of solder joints is obtained by response function analysis of the measured temperature signal. The boundary thermal resistance in a two-layered system, $\Delta R$, can be expressed as

$$
\begin{gathered}
\Delta R=\left(\frac{1}{b_{1} \tau_{1}^{1 / 2}}+\frac{1}{b_{2} \tau_{2}^{1 / 2}}\right)\left(A-A^{\prime}\right), \\
A^{\prime}=\frac{b_{1} \tau_{1}^{3 / 2}+3 b_{1} \tau_{1}^{1 / 2} \tau_{2}+3 b_{2} \tau_{1} \tau_{2}^{1 / 2}+b_{2} \tau_{2}^{3 / 2}}{6\left(b_{1} \tau_{1}^{1 / 2}+b_{2} \tau_{2}^{1 / 2}\right)}, \\
\tau=\frac{d^{2}}{\alpha},
\end{gathered}
$$

where $b, \tau, d$, and $\alpha$ are the thermal effusivity, heat diffusion time, layer thickness, and thermal diffusivity, respectively. $A$ is the experimental areal heat diffusion time of a specimen with a thermal resistance layer, obtained from the measured temperature curve. $A^{\prime}$ is the calculated one, analyzed using Eq. (2), without a boundary thermal resistance layer. The suffixes 1 and 2 represent the top-side and bottom-side Si chips, respectively. In this study, based on the assumption that all the reactive $\mathrm{Al} / \mathrm{Ni}$ bonded specimens consist of two $\mathrm{Si}$ layers, $\Delta R$ means the thermal resistance between two Si chips. Therefore, $\Delta R$ corresponds to the thermal resistance of the bonded section.

\section{Results and Discussion}

Figure 3 shows the thermal resistance measurement results of reactively bonded solder joints using the as-sputtered and free-standing $\mathrm{Al} / \mathrm{Ni}$ multilayer films. The measured values are averages of three specimens, and the error bars indicate the difference between the maximum and minimum values. Under the normal load of $3 \mathrm{MPa}$ in bonding, the thermal resistance of the joint using the as-sputtered $\mathrm{Al} / \mathrm{Ni}$ film was $2.8 \times 10^{-6} \mathrm{~m}^{2} \mathrm{KW}^{-1}$, which is approximately 4 times higher than the ideal value, $0.8 \times 10^{-6} \mathrm{~m}^{2} \mathrm{KW}^{-1}$. Many voids and cracks produced in the joint made the thermal resistance high. ${ }^{(16,18)}$ By using the free-standing $\mathrm{Al} / \mathrm{Ni}$ film, the thermal resistance decreased to $2.0 \times 10^{-6} \mathrm{~m}^{2} \mathrm{KW}^{-1}$, a $29 \%$ reduction from that of the assputtered $\mathrm{Al} / \mathrm{Ni}$ joint. In the $20 \mathrm{MPa}$ bonding, the thermal resistance decreased further to around $1.7 \times 10^{-6} \mathrm{~m}^{2} \mathrm{KW}^{-1}$, which is almost one-half that of the as-sputtered $\mathrm{Al} / \mathrm{Ni}$ joint at $3 \mathrm{MPa}$, regardless of the $\mathrm{Al} / \mathrm{Ni}$ film preparation method. We confirmed that the use of the freestanding $\mathrm{Al} / \mathrm{Ni}$ film had a positive effect on the solder joint reactively bonded at lower pressure loads. 


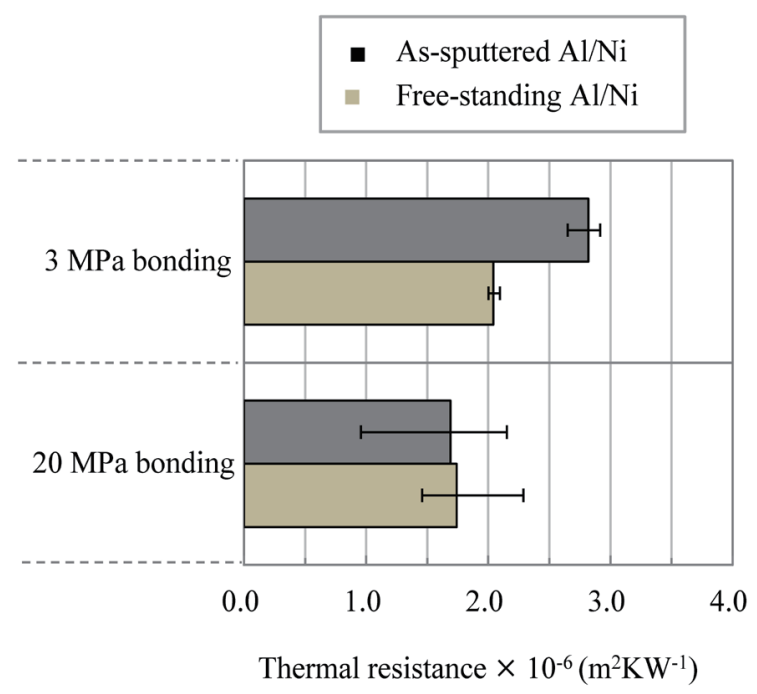

Fig. 3. (Color online) Measured thermal resistance between two Si chips. The measured values are averaged for three specimens. The error bars indicate the difference between the maximum and minimum values.

To discuss the free-standing effect, cross-sectional SEM observation was performed first, as shown in Fig. 4. The measured thermal resistance for each specimen was also described. In the cross section of the as-deposited $\mathrm{Al} / \mathrm{Ni}$ joint at $3 \mathrm{MPa}$, a number of voids are found in the solder and NiAl layers, and at the NiAl and solder interface. In the NiAl layer, there are many vertical lines with small voids, which are mechanical microcracks originating from volume shrinkage after the reaction. ${ }^{(11,20,21)}$ At $20 \mathrm{MPa}$, these voids and cracks are found to be reduced, consequently leading to a reduction in the thermal resistance by approximately $24 \%$. In the free-standing $\mathrm{Al} / \mathrm{Ni}$ joint, there are two differences from the as-sputtered $\mathrm{Al} / \mathrm{Ni}$ joint. One is the absence of visible cracks in the NiAl layer. The reacted NiAl derived from the free-standing $\mathrm{Al} / \mathrm{Ni}$ film shows a very smooth cross section in the entire bonded section. The other is flat interfaces between the $\mathrm{NiAl}$ and solder. Although the interfaces in the as-sputtered $\mathrm{Al} / \mathrm{Ni}$ joint form a convexo-concave pattern, those in the free-standing $\mathrm{Al} / \mathrm{Ni}$ joint form an almost straight line. The number of voids in the vicinity of the interface is much smaller than that in the case of the as-sputtered $\mathrm{Al} / \mathrm{Ni}$ joint.

Figure 5 shows void area fraction analysis results for the bonded section. All the data are based on the SEM images shown in Fig. 4, that is, specimens are identical to those used for SEM observation. Voids are traced and binarized for SEM images using the same analysis method as in our previous work. ${ }^{(18)}$ Three types of void fraction were quantitatively analyzed. The white, blue, and red colors indicate the void area fractions in the solder, at the top-side solder interface, and at the bottom-side solder interface, respectively. In bonding at $3 \mathrm{MPa}$, the void area fraction of the as-sputtered $\mathrm{Al} / \mathrm{Ni}$ joint was $6.0 \%$, which is broken down into 4.0, 1.7 , and $0.3 \%$ in the solder, at the bottom-side interface, and at the top-side interface, respectively. By increasing the normal load to $20 \mathrm{MPa}$, the fractions in the solder and at the bottom-side interface were halved. 


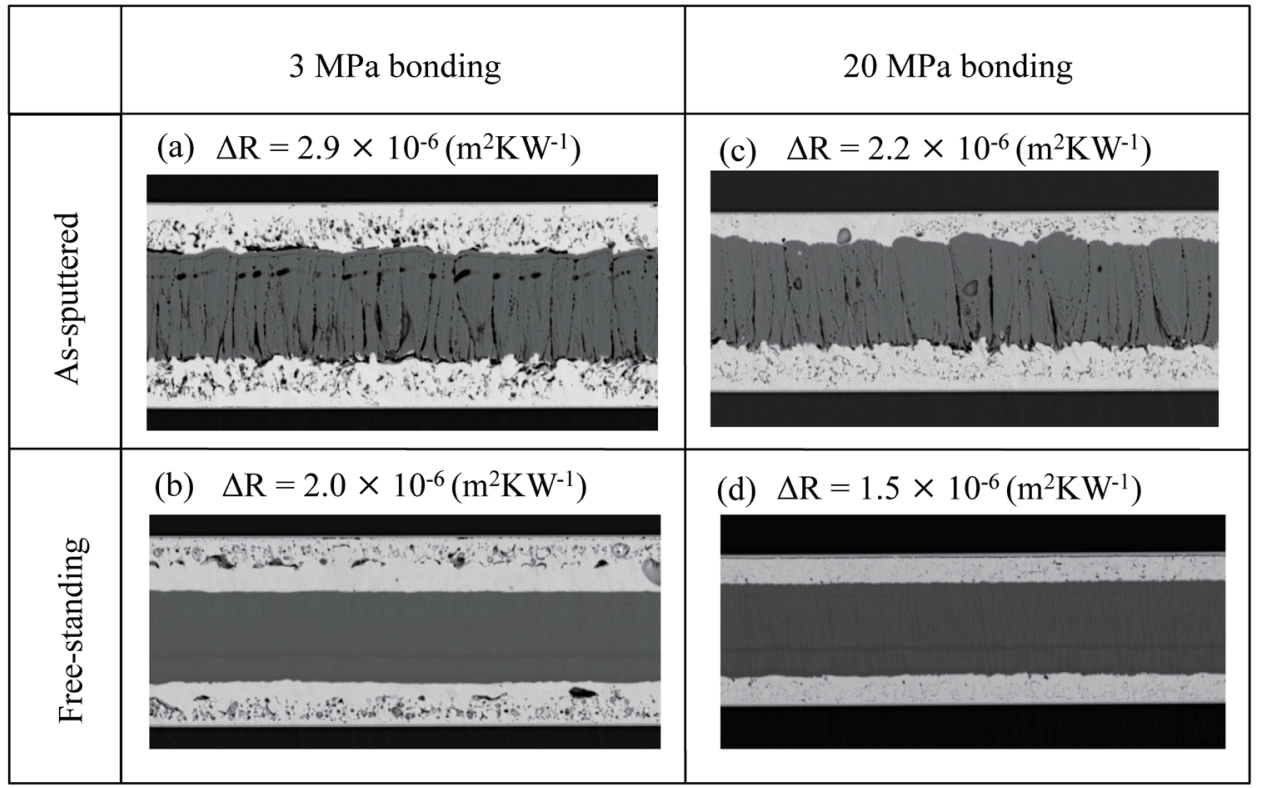

Fig. 4. Cross-sectional SEM images of the Al/Ni reactively bonded solder joints. The measured thermal resistance for each specimen is also described.

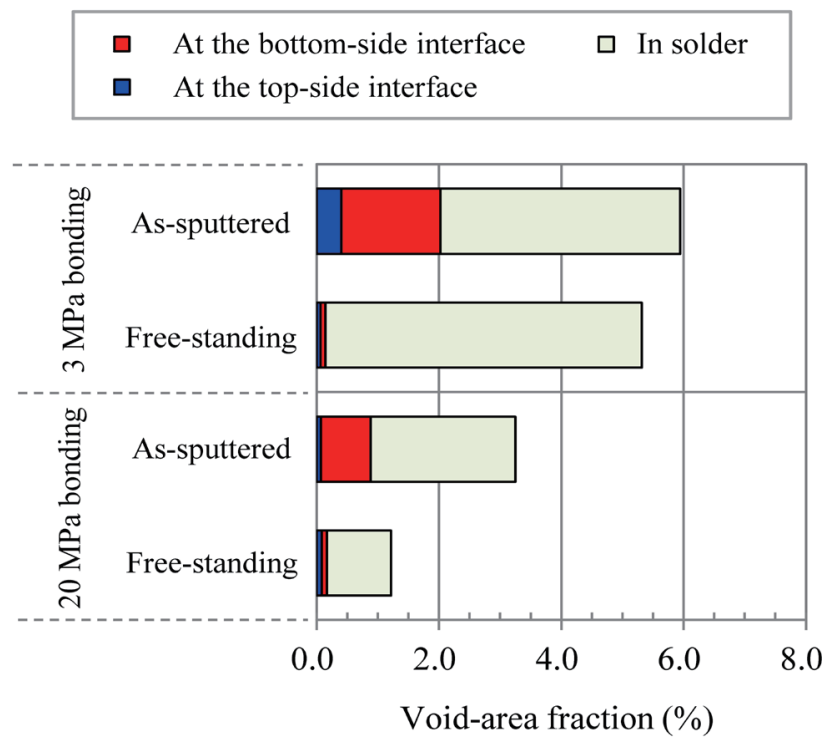

Fig. 5. (Color online) Results of void area fraction analysis for solder parts. The specimens are identical to those used for SEM observation.

These results mostly correspond to the reduction rate of the thermal resistance on increasing the pressure load from 3 to $20 \mathrm{MPa}$. In the free-standing $\mathrm{Al} / \mathrm{Ni}$ joint at $3 \mathrm{MPa}$, the whole void area fraction was $5.2 \%$, only a $14 \%$ decrease from the as-sputtered $\mathrm{Al} / \mathrm{Ni}$ joint value. In fact, 
the void fraction in the solder increased when using the free-standing $\mathrm{Al} / \mathrm{Ni}$ film. However, the thermal resistance decreased by $30 \%$, as depicted in Fig. 4. This implies that the voids in the solder did not markedly affect the thermal resistance of the solder joint because the heat path could be sufficiently secured even if a solder layer included many voids. Since the sputtering conditions for the solder, such as gas pressure and substrate temperature, were not optimized, the solder's density would be low, accounting for the remaining voids in the solder layer. In addition, note that the void fractions at the two interfaces decreased markedly to around $0.1 \%$. At $20 \mathrm{MPa}$, a similar value at the interfaces was obtained. By using a free-standing $\mathrm{Al} / \mathrm{Ni}$ film, the number of voids at the NiAl-solder interface could be reduced dramatically, leading to the reduction in the thermal resistance of the solder joints even in low-pressure bonding. In order to reduce the thermal resistance of the reactively bonded solder joint, it is significant to make the number of voids as low as possible at the NiAl-solder interface.

As indicated above, there is a distinct difference in the number of voids at the NiAl-solder interface between two joint types: the as-sputtered $\mathrm{Al} / \mathrm{Ni}$ joint and the free-standing $\mathrm{Al} / \mathrm{Ni}$ joint. To consider the reason behind this, the element distribution was examined by EPMA. Figure 6 denotes EPMA maps showing the distribution of $\mathrm{Ni}$ and $\mathrm{Al}$ atoms on the cross section of the solder joint. In all the specimens, $\mathrm{Ni}$ and $\mathrm{Al}$ were found to be distributed in the layer where the Al/Ni multilayer was changed to a single NiAl intermetallic compound. As already shown in Fig. 4, it can be clearly confirmed that solder joints using as-sputtered Al/Ni films have an irregularly shaped interface between the NiAl and solder layers. Note that the Al-rich lines were observed in the joints using the free-standing $\mathrm{Al} / \mathrm{Ni}$ films. In addition, the whole NiAl layer was slightly thicker than the as-sputtered Al/Ni layer. Possibly, the disturbance of the sputtering rate can cause the localization of the $\mathrm{Al}$ layer and decrease the $\mathrm{Al} / \mathrm{Ni}$ layer thickness during the deposition. In the solder layer, it can be seen that little $\mathrm{Al}$ is distributed, whereas $\mathrm{Ni}$ is intermittently distributed. This indicates that $\mathrm{Ni}$ easily diffused into the $\mathrm{SnAg}$ solder layer because Ni has good chemistry with $\mathrm{Sn} .{ }^{(18,22,23)}$ In the as-sputtered Al/Ni joint, Ni diffused more under higher pressure loads in bonding. This indicates that higher pressure loads caused a higher heat conduction efficiency from $\mathrm{Al} / \mathrm{Ni}$ to the solder. ${ }^{(16)} \mathrm{Ni}$ was more markedly distributed in the top-side solder than in the bottom-side solder. Since the Al/Ni-solder interface on the top side is a newly bonded free surface, the interfacial thermal resistance is higher on the top side than on the bottom side. This would have affected the Ni diffusion during the Al/Ni reaction. That is, the interfacial resistance could cause the temperature to change slowly; a high temperature is well known to enhance atomic diffusion in metals. ${ }^{(24,25)}$ Therefore, the top-side solder may be heated more slowly and its temperature might remain higher than the melting point for a longer time than the bottom-side solder. As a result, Ni would diffuse further into the top-side solder. ${ }^{(16)}$

On the other hand, the amount of diffused $\mathrm{Ni}$ was lower in the free-standing $\mathrm{Al} / \mathrm{Ni}$ joint than in the as-sputtered $\mathrm{Al} / \mathrm{Ni}$ joint. In the case of the free-standing $\mathrm{Al} / \mathrm{Ni}$ joint, the top- and bottom-side interfaces are the newly bonded free surface. That is, since there are two thermally separated interfaces, it can be easy for more $\mathrm{Ni}$ to diffuse into the solder than in the case of the as-sputtered $\mathrm{Al} / \mathrm{Ni}$ joint. The heat conduction efficiency is expected to be better in the case of the free-standing $\mathrm{Al} / \mathrm{Ni}$ joint. Nevertheless, the actual trend was the complete opposite. In 

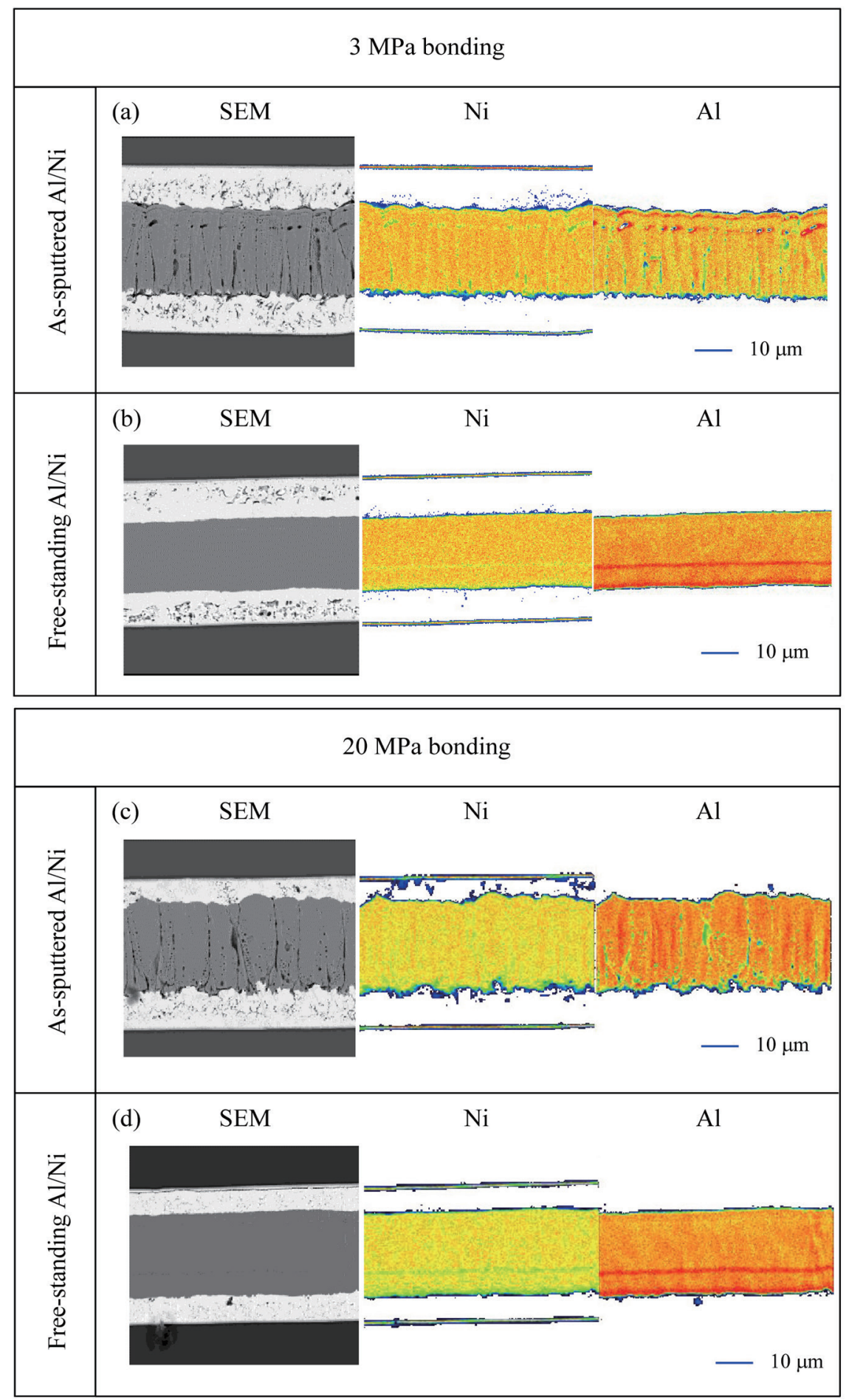

Fig. 6. (Color online) Element mapping images obtained by EPMA. Using (a), (c) as-sputtered and (b), (d) freestanding $\mathrm{Al} / \mathrm{Ni}$ films. 
addition, the number of voids at the NiAl-solder interface was less than in the case of the assputtered $\mathrm{Al} / \mathrm{Ni}$. These results suggest that the heat conduction efficiency during reactive bonding is unrelated to the number of voids at the interface.

To investigate the heat-affected area in the solder layer in more detail, Fig. 7 shows the grain size maps of solder layers analyzed by EBSD. The difference in color is indicative of that in crystal orientation angle, whose threshold angle used to divide grains was set to $5^{\circ}$ in this work. The grain size in the solder layer of the as-sputtered $\mathrm{Al} / \mathrm{Ni}$ joint is likely to be larger than that of the free-standing $\mathrm{Al} / \mathrm{Ni}$ joint. The cross-sectional area percentages of crystal grains with diameters larger than $7 \mathrm{~mm}$, indicated in red, are 25.2 and $8.5 \%$ on the bottom side for the as-sputtered and free-standing $\mathrm{Al} / \mathrm{Ni}$ joints, respectively. In the free-standing $\mathrm{Al} / \mathrm{Ni}$ joint, the grains on the NiAl side seem to be somewhat larger than those on the Si side. As a common understanding, grain size is fully influenced by annealing temperature and time because a crystal grain grows at elevated temperatures. ${ }^{(26,27)}$ If this knowledge is applied, the solder layer in the as-sputtered $\mathrm{Al} / \mathrm{Ni}$ joint would be expected to be subjected to heat generated by an $\mathrm{Al} / \mathrm{Ni}$ exothermic reaction more than that in the free-standing $\mathrm{Al} / \mathrm{Ni}$ joint. That is, the heat-affected solder area would be smaller in the case of using the free-standing film. This might be caused by the reduced exothermic efficiency resulting from the localization of the Al layer and the smaller thickness of the deposited Al/Ni layer, as indicated above. EPMA and EBSD results imply that the heat conduction efficiency during the reactive soldering might not affect the number of voids generated at the interface.

In the case of the exothermic reaction in the $\mathrm{Al} / \mathrm{Ni}$ multilayer film having the atomic ratio of $1: 1$, the reacted NiAl layer definitely shrinks by $12 \%$ in volume after the reaction because of the decrease in lattice spacing to one-half as well as the change in crystal structure from fcc to bcc. ${ }^{(11)}$ The volume shrinkage possibly affects the mechanical reliability of the bonded section. In fact, the reacted NiAl layer in the free-standing $\mathrm{Al} / \mathrm{Ni}$ joint showed a very smooth cross

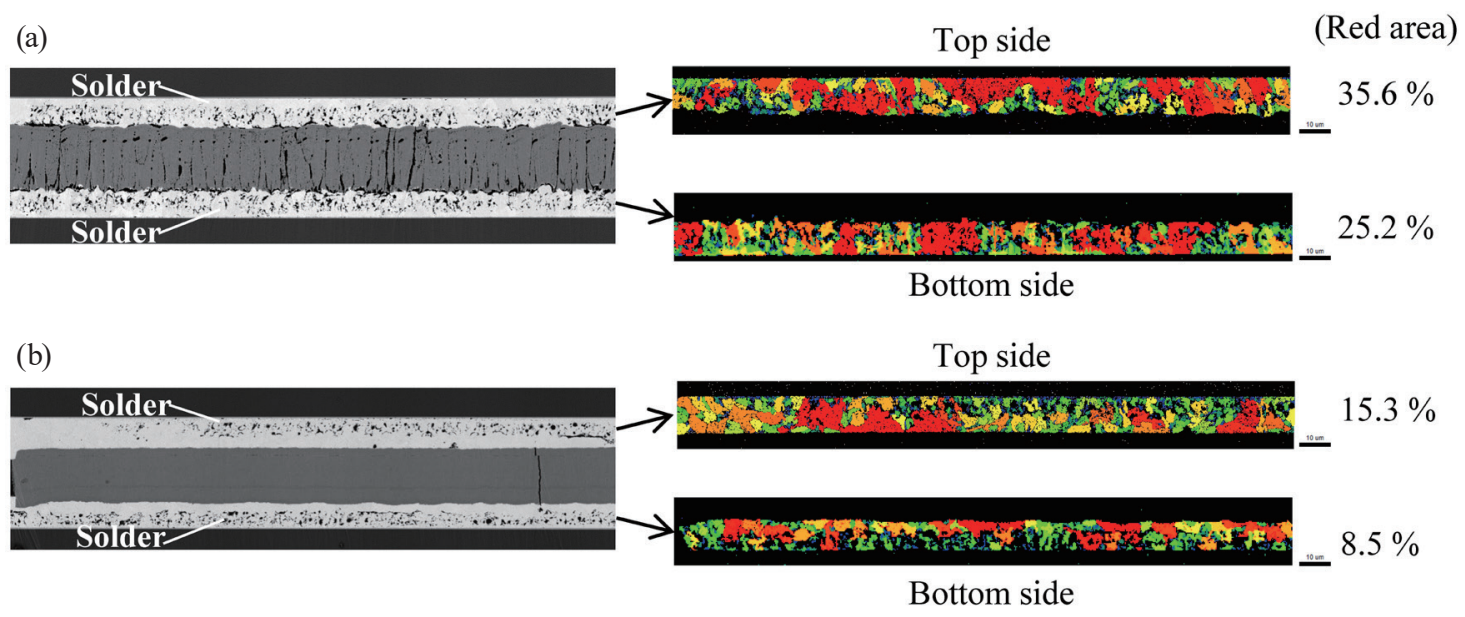

Fig. 7. (Color online) Grain size maps of solder layers analyzed by EBSD: cases of using (a) as-sputtered and (b) free-standing $\mathrm{Al} / \mathrm{Ni}$ films. The specimens for the analysis were bonded at $3 \mathrm{MPa}$. 
section without visible cracks or defects, whereas the NiAl layer in the as-sputtered $\mathrm{Al} / \mathrm{Ni}$ joint had numerous cracks, shown as vertical grooves in Figs. 4 and 7. This difference in the degree of cracking is probably caused by the difference in mechanical restriction of volume shrinkage; that is, since the as-sputtered $\mathrm{Al} / \mathrm{Ni}$ film was tightly restricted to the bottom-side Si chip, its shrinkage was impeded during NiAl intermetallic compound formation, consequently causing the generation of cracks. Also, voids detected at the interface between the NiAl and bottomside solder layers would be related to the mechanical restriction of volume shrinkage. On the basis of these experimental findings, we consider that mechanical restriction as well as heat conduction gave rise to the increased thermal resistance of the reactively bonded solder joint.

Figure 8 illustrates a stress model for void and crack generation mechanisms. In a solder layer deposited by sputtering on a Si substrate, a minute tensile stress is thought to be produced at room temperature because the thermal expansion coefficient of $\mathrm{SnAg}$ is clearly higher than that of $\mathrm{Si}^{(26,27)}$ Owing to stress balancing, a small compressive stress is thought to be produced in the $\mathrm{Si}$ and $\mathrm{Al} / \mathrm{Ni}$ layers in the vicinity of the $\mathrm{SnAg}$-deposited interface. Before bonding, there is no stress in the free-standing $\mathrm{Al} / \mathrm{Ni}$ film, whereas there is a stress slope in the assputtered $\mathrm{Al} / \mathrm{Ni}$ film because of the small tensile stress generated in the solder layer. During bonding, the $\mathrm{Al} / \mathrm{Ni}$ multilayer film changes to the NiAl alloy, whereby the volume shrinks by $12 \%$. Although a uniform compressive stress is produced in the NiAl layer originating from the free-standing $\mathrm{Al} / \mathrm{Ni}$ film, a complex stress state with a large stress slope is obtained in the NiAl layer originating from the as-sputtered film. This is because there is a mechanical restriction imbalance between the top and back surfaces of the $\mathrm{Al} / \mathrm{Ni}$ film. Then, a very

【Before bonding】

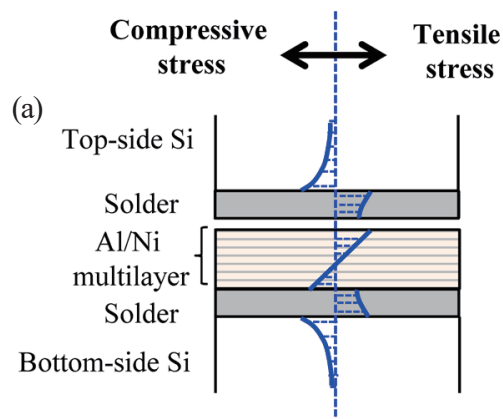

(b)

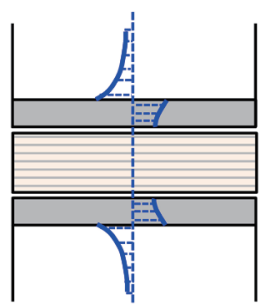

【During bonding】
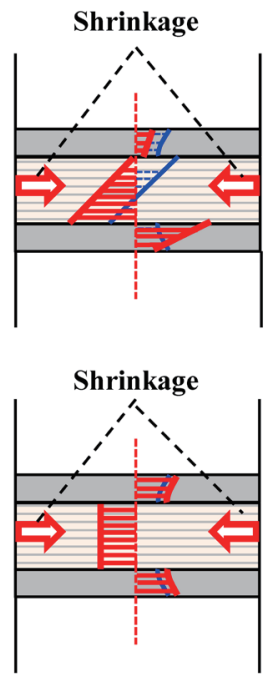

【After bonding】
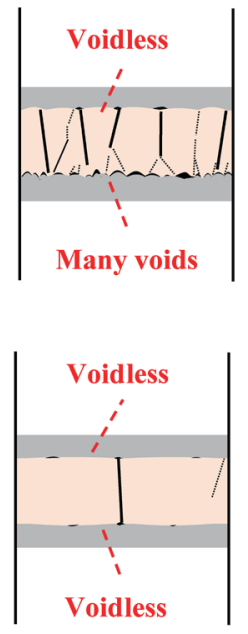

Fig. 8. (Color online) Stress balance model for void generation: cases of using (a) as-sputtered Al/Ni and (b) freestanding $\mathrm{Al} / \mathrm{Ni}$ films. 
large stress mismatch is generated in the NiAl and bottom-side solder interface; consequently, after bonding, many voids and cracks are produced at the interface and in the NiAl layer, respectively. When using a free-standing $\mathrm{Al} / \mathrm{Ni}$ multilayer film, balancing the stress between the top and back surfaces of the $\mathrm{Al} / \mathrm{Ni}$ film is important and will realize a reactively bonded solder joint having low thermal resistance as well as high mechanical reliability.

The theoretical thermal resistance of the $\mathrm{Al} / \mathrm{Ni}$ reactively bonded solder joint is $0.8 \times 10^{-6} \mathrm{~m}^{2} \mathrm{KW}^{-1}$, calculated on the basis of the nominal thermal conductivity of each material. This is about one-half the minimum resistance $\left(1.5 \times 10^{-6} \mathrm{~m}^{2} \mathrm{KW}^{-1}\right)$ obtained using the free-standing $\mathrm{Al} / \mathrm{Ni}$ film under $20 \mathrm{MPa}$ bonding. The difference is calculated to be $0.7 \times 10^{-6} \mathrm{~m}^{2} \mathrm{KW}^{-1}$, which might be due mainly to microcracks in the reacted NiAl layer. In analyzing the resistance within a range from 10 to $30 \%$ in the crack-area fraction, the crack contribution was estimated to range from $0.4 \times 10^{-6}$ to $0.5 \times 10^{-6} \mathrm{~m}^{2} \mathrm{KW}^{-1}$ in our previous work. ${ }^{(18)}$ To bring the experimental thermal resistance closer to the theoretical value, eliminating voids in the $\mathrm{SnAg}$ solder will be effective.

\section{Conclusions}

In this study, the effect of the use of a free-standing $\mathrm{Al} / \mathrm{Ni}$ multilayer film on the thermal resistance of a reactively bonded solder joint was investigated. The use of a free-standing $\mathrm{Al} / \mathrm{Ni}$ film enabled us to reduce the thermal resistance by $29 \%$ from the value obtained using an as-sputtered $\mathrm{Al} / \mathrm{Ni}$ film at a bonding pressure load of $3 \mathrm{MPa}$. At $20 \mathrm{MPa}$, no marked freestanding effect was obtained because the number of voids at the NiAl-solder interface could be reduced even with the as-sputtered $\mathrm{Al} / \mathrm{Ni}$ film. The reactively bonded solder joint derived from the free-standing $\mathrm{Al} / \mathrm{Ni}$ film exhibited almost no visible microcracks and very few voids at the interface. The results of EPMA and EBSD analyses suggested that the free-standing effect was probably associated not with heat conduction, but with mechanical restriction of the bottom-side solder layer on $\mathrm{Si}$. On the basis of experimental findings, we proposed a stress balance model for explaining crack and void generation mechanisms. Using a free-standing Al/Ni multilayer film will be effective for achieving low thermal resistance and high mechanical reliability of a reactively bonded solder joint. To further reduce the thermal resistance, it will be necessary to eliminate microcracks completely in the reacted NiAl layer.

\section{References}

1 J. S. Kim, T. Lagrange, B. W. Reed, M. L. Taheri, M. R. Armstrong, W. E. King, N. D. Browning, and G. H. Campbell: Science 321 (2008) 1468.

2 J. C. Trenkle, L. J. Koerner, M. W. Tate, N. Walker, S. M. Gruner, T. P. Weihs, and T. C. Hufnage: J. Appl. Phys. 107 (2010) 113511.

3 O. Politano, F. Baras, A. S. Mukasyan, S. G. Vadchenko, and A. S. Rogachev: Surf. Coat. Technol. 215 (2013) 485.

4 S. Simões, F. Viana, and M. F. Vieira: J. Mater. Eng. Perform. 23 (2014) 5.

5 P. Swaminathan, M. D. Grapes, K. Woll, S. C. Barron, D. A. LaVan, and T. P. Weihs: J. Appl. Phys. 113 (2013) 143509.

6 A. S. Rogachev, S. G. Vadchenko, and A. S. Mukasyan: Appl. Phys. Lett. 101 (2012) 063119.

7 M. D. Grapes, T. LaGrange, K. Woll, B. W. Reed, G. H. Campbell, D. A. LaVan, and T. P. Weihs: APL Mater. 2 (2014) 116102. 
8 J. Wang, E. Besnoin, A. Duckham, S. J. Spey, M. E. Reiss, O. M. Knio, M. Powers, M. Whitener, and T. P. Weihs: Appl. Phys. Lett. 83 (2003) 3987.

9 T. Namazu, H. Takemoto, H. Fujita, Y. Nagai, and S. Inoue: Proc. 19th IEEE Int. Conf. Microelectromechanical Systems (2006) 286.

10 I. Nakita: Materiali in Tehnologije 43 (2009) 3.

11 T. Namazu, K. Ohtani, K. Yoshiki, and S. Inoue: Proc. Transducers (2011) 1368.

12 Y. P. Zhang, Y. Q. Yang, J. L. Yi, and H. C. Hu: Mater. Trans. 54 (2013) 931.

13 T. Namazu, K. Ohtani, S. Inoue, and S. Miyake: J. Eng. Mater. 137 (2015) 031011.

14 S. Miyake, K. Ohtani, S. Inoue, and T. Namazu: J. Eng. Mater. 138 (2015) 011006.

15 S. Miyake, S. Kanetsuki, K. Morino, J. Kuroishi, and T. Namazu: Jpn. J. Appl. Phys. 54 (2015) 06FP15.

16 S. Kanetsuki, S. Miyake, K. Kuwahara, and T. Namazu: Jpn. J. Appl. Phys. 55 (2016) 06 GP17.

17 J. Shen, Y. C. Chan, and S. Y. Liu: Acta Mater. 57 (2009) 5196.

18 S. Kanetsuki, K. Kuwahara, S. Egawa, S. Miyake, and T. Namazu: Jpn. J. Appl. Phys. 56 (2017) 06GN16.

19 T. Baba: Jpn. J. Appl. Phys. 48 (2009) 05EB04.

20 X. Qiu and J. Wang: Sens. Actuators, A 141 (2008) 476.

21 J. Wang, E. Besnoin, A. Duckham, S. J. Spey, M. E. Reiss, O. M. Knio, and T. P. Weihs: J. Appl. Phys. 95 (2004) 248.

22 T. Watanabe, I. Okane, and K. Sasabe: Yosetsu Gakkaishi 48 (1979) 536 (in Japanese).

23 T. Watanabe, I. Okane, and K. Sasabe: Yosetsu Gakkaishi 48 (1979) 611 (in Japanese).

24 D. C. Yh and H. B. Huntington: Phys. Rev. Lett. 53 (1984) 2185.

25 S. K. Seo, S. K. Kang, M. G. Cho, D. Y. Shih, and H. M. Lee: J. Electron. Mater. 38 (2009) 2461.

26 C. Cai, R. An, C. Wang, Y. Tian, and X. Ji: J. Mater. Sci. - Mater. Electron. 29 (2018) 8287.

27 X. Long, W. Tang, S. Wang, X. He, and Y. Yao: J. Mater. Sci. - Mater. Electron. 29 (2018) 7177. 